\title{
Competitividade e orientação regional das exportações brasileiras de uva
}

\author{
Leticia Favaretto" \\ Juliana Favaretto** \\ Fernanda Cigainski Lisbinski"*** \\ Daniel Arruda Coronel ${ }^{* * * * *}$
}

\begin{abstract}
Resumo
Este estudo buscou analisar a competitividade e a orientação regional das exportações de uvas frescas produzidas no Brasil, no período 2000 a 2017. Para atingir esse objetivo, utilizaram-se os seguintes indicadores de comércio internacional: Índice de Vantagem Comparativa Revelada (IVCR), Taxa de Cobertura (TC) e Índice de Orientação Regional (IOR). Os resultados indicam que, na maior parte do período analisado, o Brasil teve vantagem comparativa revelada. Além disso, durante todo o período, as exportações superaram as importações, e as exportações possuem forte orientação para os dois principais importadores do produto, que são Holanda e Reino Unido. Entretanto, o produto vem perdendo espaço no comércio internacional, portanto, é necessário que haja maiores incentivos à produção de uva para que o país consiga maior inserção nesse mercado, que possui grande potencial.
\end{abstract}

Palavras-chave: Uvas frescas. Competitividade. Orientação.

* Discente do Curso de Graduação em Ciências Econômicas da Universidade Federal de Santa Maria (UFSM) e Bolsista de Iniciação Científica (Pibic) do CNPq. E-mail: leticiafavaretto18@gmail.com

** Discente do Curso de Graduação em Ciências Econômicas da UFSM e Bolsista de Iniciação Científica (Pibic) do CNPq. E-mail: julianafavaretto07@hotmail.com

**** Discente do Programa de Pós-Graduação em Economia e Desenvolvimento da UFSM. E-mail: fernandac132@hotmail.com

***** Professor Associado do Curso de Graduação em Ciências Econômicas e dos Programas de Pós-Graduação de Economia e Desenvolvimento, Gestão de Organizações Públicas e Agronegócios da UFSM e Bolsista de Produtividade do CNPq/UFSM. E-mail: daniel.coronel@uol.com.br

http://doi.org/10.5335/rtee.v26i54.11392

Submissão: 26/07/2020. Aceite: 06/10/2020.

Teoria e Evidência Econômica - a. 26, n. 54, p. 7-32, jan./jun. 2020 


\section{Introdução}

Em 2018, as frutas frescas geraram US $\$ 8,2$ bilhões em exportações totais mundiais. Comparado ao ano de 2017, em 2018, as exportações de frutas cresceram 11,3\%, passando de US $\$ 7,37$ bilhões para US $\$ 8,2$ bilhões. Destaca-se que o comércio de frutas representa $0,045 \%$ do comércio mundial total. Os principais exportadores são Tailândia (20\%), Nova Zelândia (18,66\%), Vietnã (8,8\%), Itália $(6,6 \%)$ e Hong Kong $(5,4 \%)$. E os principais mercados de destino dessas frutas são União Europeia (53,6\%), Estados Unidos (18,9\%), China (13,9\%), Rússia (5,1\%) e Canadá (4,8\%) (OBSERVATORY OF ECONOMIC COMPLEXITY, 2020).

Dentro do agronegócio brasileiro, a fruticultura é um setor muito importante, pois, além de ser uma atividade bastante rentável para os produtores, emprega quantidade expressiva de mão de obra e tem um enorme potencial como alternativa para expansão das exportações de produtos agrícolas (VITTI, 2009). Além disso, o mercado de hortifrútis conta com boas perspectivas de expansão, devido a mudanças no padrão de consumo, em que há maior preocupação dos consumidores com a sua alimentação e com problemas relacionados a obesidade, colesterol, entre outros, fazendo com que os consumidores optem por produtos mais saudáveis, ricos em vitaminas e sais minerais (ALVES, 2009).

Em 2017, a China foi a maior produtora de frutas no mundo, seguida da Índia e do Brasil, que ocupou a terceira posição (SECRETARIA DE AGRICULTURA E ABASTECIMENTO DO PARANÁ, 2020). No entanto, de acordo com a Associação Brasileira de Produtores Exportadores de Frutas e Derivados (ABRAFRUTAS) (2019a), embora o Brasil seja o terceiro maior produtor de frutas no mundo, apenas $3 \%$ do que é produzido destina-se ao mercado externo, por isso o país ocupa a modesta $23^{\underline{a}}$ posição no ranking de exportações. Nesse sentido, o Brasil tem buscado ampliar sua participação na comercialização de frutas no mercado internacional. Em 2019, o volume de exportações aumentou 16\% em relação a 2018, passando de 848 milhões de toneladas para 980 milhões de toneladas, e a uva foi a terceira fruta que mais gerou receitas de exportação, ficando atrás somente da manga e do melão (ABRAFRUTAS, 2020). Dessa forma, evidenciam-se a importância da uva na pauta de exportações brasileiras e o seu impacto na geração de renda e divisas para o país.

A produção de uvas no Brasil ocorre em diversos estados, sendo a Região Sul a maior produtora, com destaque para o estado do Rio Grande do Sul, e a Região 
Nordeste é a segunda maior produtora, mais especificamente o Vale do São Francisco, que engloba os estados da Bahia e de Pernambuco (MELLO, 2018). Entretanto, no que diz respeito às exportações, no ano de 2019, os dados do Ministério da Economia, Indústria, Comércio Exterior e Serviços (BRASIL, 2020) indicaram que o Vale do São Francisco foi responsável por aproximadamente 98,5\% das exportações nacionais de uva, o que destaca a relevância das exportações da fruta para a geração de emprego e renda nessa região.

Diante disso, o objetivo deste artigo é analisar a competitividade, o desempenho e a orientação das exportações de uvas frescas brasileiras no comércio internacional, no período de 2000 a 2017. Para atingir esse objetivo, foram utilizados os seguintes indicadores de comércio internacional: Índice de Vantagem Comparativa Revelada (IVCR), Taxa de Cobertura (TC) e Índice de Orientação Regional (IOR).

$\mathrm{Na}$ literatura, encontram-se alguns trabalhos que analisaram a competitividade das uvas brasileiras, como os de Amaral et al. (2016), Silva, Ferreira e Lima (2016) e Silva Filho, Santos e Silva (2017), todos sob uma perspectiva regional, mas o diferencial deste estudo é fazer uma análise das exportações do país como um todo e analisar a orientação das exportações. A relevância desta pesquisa está no fato de que os resultados podem ajudar na tomada de decisões e elaborações de políticas públicas voltadas ao setor produtor de uvas para exportação, a fim de dinamizar a produção e promover maior inserção do produto no mercado internacional.

$\mathrm{O}$ artigo estrutura-se em quatro seções, além desta introdução. Na seção dois, é apresentado o referencial teórico, no qual são discutidas as principais teorias do comércio internacional, bem como uma breve revisão de literatura acerca dos indicadores de competividade utilizados; na seção três, são apresentados os procedimentos metodológicos da pesquisa; na seção quatro, apresentam-se os resultados; e, na última seção, são apresentadas as conclusões.

\section{Referencial teórico}

O comércio internacional consolidou-se após a formação do Estado Moderno, no entanto, tal prática ocorre desde os primórdios da humanidade (REZENDE FILHO, 2008). Ao longo da história, vários economistas se dedicaram a compreender as razões pelas quais os países comercializavam entre si e, assim, formularam suas teorias acerca do comércio internacional. 
No ano de 1776, Adam Smith apresentou a teoria das Vantagens Absolutas em seu livro intitulado A riqueza das nações: investigações sobre a natureza e suas causas, no qual postulava que uma nação deveria se especializar na produção das commodities em que possuísse vantagens absolutas ${ }^{1}$ e trocar parte dessa produção por commodities que produzisse em desvantagens absolutas (SALVATORE, 1998). Entretanto, sua teoria continha algumas limitações, entre elas, o fato de que, se um determinado país não possuísse vantagem absoluta em nenhum produto, não poderia participar do comércio internacional (RAINELLI, 1998).

Em 1817, David Ricardo publicou o livro Princípios de economia política e tributação, nele apresenta a teoria das Vantagens Comparativas ${ }^{2}$. Buscando corrigir as falhas da teoria de Adam Smith, a teoria de Ricardo propõe que, mesmo que uma nação não possua vantagem absoluta na produção de commodities, esta teria possibilidade de comércio internacional ao especializar-se na produção da commodity de menor desvantagem absoluta, alocando seus recursos de forma que venha a garantir a maximização da produção.

Krugman e Obstfeld (2001) fizeram algumas observações a respeito do modelo ricardiano e afirmaram que, no mundo real, nenhum país se especializa na produção de somente um produto. A especialização extrema não ocorre devido a alguns fatores, tais como a existência de mais de um fator de produção, o protecionismo e, em alguns casos, o alto custo de transporte, que inviabiliza a importação de certos produtos e faz com que os países sejam autossuficientes em determinados setores.

Anos mais tarde, Eli Heckscher e Bertil Ohlin desenvolvem a teoria neoclássica do comércio internacional ou teoria de Heckscher-Ohlin. Essa teoria pressupõe que as vantagens comparativas do comércio internacional ocorrem devido às diferenças de recursos entre os países. Segundo o Teorema de Heckscher-Ohlin, cada nação exportará a commodity que for intensiva em seu fator de produção abundante e importará a commodity que for intensiva em seu fator de produção escasso e de maior custo (WILLIAMSON, 1998). Para Gremaud et al. (2010, p. 551):

[...] a diferença entre a teoria das vantagens comparativas de Ricardo e a teoria neoclássica é que, enquanto a primeira postula que todos os países envolvidos no comércio internacional possuem a mesma função de produção e estrutura tecnológica, a segunda diz que as diferenças de tecnologias são cruciais para explicar as diferenças de custos e padrão de comércio.

Novas abordagens foram desenvolvidas visando maiores robustez e consistência nos resultados mensurados por meio de modelos teóricos de comércio internacional. O Índice de Vantagem Comparativa Revelada (IVCR), formulado por 
Balassa (1965), é um destes e busca comparar as vantagens dos produtos entre as regiões, considerando-se tal vantagem como revelada, pois seu cálculo baseia-se em dados pós-comércio. Contudo, esse índice possui limitações, pois desconsidera questões relacionadas ao protecionismo e a mudanças no câmbio. Além disso, esse índice trata importações e exportações separadamente, quando a vantagem comparativa está relacionada ao comércio líquido (BOWEN, 1983).

Outros métodos utilizados para explicar os fluxos de comércio internacional são o Índice de Taxa de Cobertura (TC), que verifica se a região ou o país é comprador ou vendedor do produto no comércio mundial, e o Índice de Orientação Regional (IOR) formulado por Yeats (1997), o qual procura analisar o destino das exportações. De acordo com Colle et al. (2014), o IOR foi utilizado inicialmente na literatura brasileira para analisar os impactos da formação do Mercosul no período de 1988 a 1994. É um método útil, mas apresenta algumas limitações, visto que não trata de questões de eficiência na produção e as informações transmitidas são restritas a um único ponto do tempo, o que dificulta a percepção de vários fatores, como vantagem comparativa, custos de transporte e barreiras comerciais (COLLE et al., 2014).

Diante disso, vários são os estudos que se utilizam desses métodos para explicar fenômenos atrelados ao comércio internacional. Destacam-se, neste estudo, os que tratam da competitividade e do desempenho das exportações frutíferas, especialmente da uva, tendo como análise as exportações do país, dos estados ou de regiões específicas. Silva et al. (2011) avaliaram o comportamento das exportações brasileiras de mamão e se as exportações do produto estão sendo orientadas para países da União Europeia e do Tratado Americano de Livre Comércio (Nafta). Para isso, utilizaram o modelo Constant-Market-Share, os índices de Orientação Regional (IOR) e de Cobertura (IC). O período analisado corresponde aos anos de 1995 a 2008. Os principais resultados demonstraram que o efeito que apresentou maior contribuição para o desempenho das exportações brasileiras de mamão, no primeiro período, foi a competitividade, seguido, no segundo período, pelo comércio mundial e pelo efeito destino das exportações. O IOR indicou que as exportações da fruta estão mais direcionadas para os países da União Europeia do que para os do Nafta. E o IC constatou que o Nafta emitiu maior número de notificações ao mamão brasileiro se comparado ao bloco europeu.

Brandão et al. (2012) verificaram, por meio do Índice de Orientação Regional (IOR), se as exportações brasileiras de café estão sendo destinadas aos principais importadores. O período de análise compreendeu os anos de 2000 a 2009. Os 
resultados demonstraram que as exportações de café são cada vez menos direcionadas para Canadá, Países Baixos, França, Itália, Bélgica, Espanha e Eslovênia, e mais voltadas para Suécia, Finlândia, Japão, Alemanha e EUA.

Silva et al. (2015) analisaram o comportamento do mercado exportador de frutas nordestinas e a existência de vantagens comparativas nas exportações dessas commodities. Para isso, utilizaram-se do Índice de Vantagem Comparativa Revelada (IVCR) e do Índice de Orientação Regional (IOR). O período analisado correspondeu aos anos de 1999 a 2013. Os resultados apontaram que a Região Nordeste apresentou vantagens comparativas reveladas na produção de frutas quando comparada às demais regiões do mundo. Porém, o IOR apontou que as exportações de frutas nordestinas estão sendo orientadas para os países europeus.

A manga e a uva figuram entre as principais frutas exportadas pelo país em termos de valor monetário, e esse fato motivou Silva, Ferreira e Lima (2016) a estudarem a competitividade das exportações desses produtos no Vale Submédio do São Francisco. Para isso, utilizaram o método de Constant-Market-Share (CMS) e o Índice de Vantagem Comparativa Revelada de Vollrath (RCAV). Ambas as frutas apresentaram vantagem comparativa revelada para todo o período analisado, sendo mais elevados os resultados para a uva. Em relação às fontes de crescimento das exportações de manga e uva, o efeito competitividade foi o maior impulsionador do aumento das exportações para o período.

Amaral et al. (2016) analisaram o desempenho das exportações de uvas na região do Vale do Rio São Francisco comparando-as às produções das Regiões Sul e Sudeste do país, no período de 2005 a 2014. Para estudar a competitividade das exportações de uvas, os autores usaram alguns indicadores, a saber: Índice de Vantagem Comparativa Revelada (IVCR), Taxa de Cobertura (TC), Índice de Contribuição ao Saldo Comercial (ICSC) e Posição Relativa de Mercado (PRM). Os resultados indicaram que o Vale do Rio São Francisco possui maior competitividade no mercado exportador, contudo, Sul e Sudeste se destacam pelo volume de produção.

Ainda com relação às exportações de uvas, Silva Filho, Santos e Silva (2017) buscaram analisar a sua competitividade no estado de Pernambuco. Metodologicamente, utilizaram-se da construção de indicadores clássicos de comércio internacional, tais como o Índice de Vantagem Comparativa (VRE) e Competitividade Revelada (CRV). Os resultados revelaram que, apesar da alta competitividade internacional, as exportações de uvas de mesa mantiveram-se elevadas ao longo do período 1997-2016. O indicador de vantagem comparativa revelou um desempenho 
acentuado do produto na pauta de exportação do estado. Em relação à competitividade revelada, os resultados foram significativos na maioria dos anos analisados.

Santos e Sousa (2017) propuseram-se a analisar a competitividade das exportações do melão produzido no Ceará, no Rio Grande do Norte, na Bahia e em Pernambuco, para o período de 2000 a 2015 . No estudo, foram empregados os Índices de Vantagem Comparativa Revelada e de Vantagem Comparativa Revelada de Vollrath. Além desses índices, foi empregado também o modelo Constant-Market-Share, com o intuito de identificar as fontes de crescimento das exportações do produto. Os indicadores de competitividade revelaram que o Rio Grande do Norte e o Ceará possuem vantagens comparativas para o melão. Além disso, a competitividade e o crescimento do comércio mundial mostraram-se como efeitos mais importantes para o crescimento das exportações na comparação entre subperíodos.

Após, Santos e Sousa (2019), em novo trabalho, analisaram a competitividade das exportações de banana dos estados do Ceará, do Rio Grande do Norte, do Rio Grande do Sul, de Santa Catarina e do Paraná, tendo como base o período de 2003 a 2017. Os autores utilizaram os Índices de Vantagem Comparativa Revelada de Balassa (IVCR), Vantagem Comparativa Revelada Simétrica (IVCRS) e Vantagem Comparativa Revelada de Vollrath (RCAV) e o modelo Constant Market Share. Os resultados apontaram que os estados do Rio Grande do Norte e de Santa Catarina apresentaram vantagem comparativa em relação ao Brasil, já o Paraná apresentou desvantagem comparativa nas exportações da fruta, conforme resultados do IVCR, do IVCRS e do RCAV. Por meio dos índices utilizados, os autores verificaram a presença de vantagem comparativa nas exportações de banana para o Ceará, a partir de 2006, e para o Rio Grande do Sul, de 2012 a 2015. Com relação ao resultado do modelo Constant Market Share, o efeito destino das exportações foi o que mais contribuiu no desempenho das exportações de banana, e o efeito competitividade foi determinante no terceiro período analisado.

\section{Metodologia}

Nesta seção, apresenta-se o método analítico do estudo, por intermédio de três indicadores, que são Índice de Vantagem Comparativa Revelada (IVCR), Taxa de Cobertura (TC) e Índice de Orientação Regional (IOR). Por meio desses índices, o presente trabalho busca analisar a competitividade da uva brasileira e o desempenho das suas exportações. 


\section{Índice de Vantagem Comparativa Revelada}

O Índice de Vantagem Comparativa Revelada (IVCR) mede a intensidade da especialização do comércio internacional de um país relativamente a uma região ou ao mundo, é fundamentado na Lei das Vantagens Comparativas de David Ricardo e foi proposto inicialmente por Bela Balassa (1965). O indicador de IVCR é apresentado na Equação (1):

$$
V C R_{i j}=\frac{\left(X_{i j} / X_{i}\right)}{\left(X_{z j} / X_{z}\right)}
$$

Em que: $X_{i j}=$ representa o valor das exportações brasileiras do produto $j ; X_{i}$ $=$ representa $\mathrm{o}$ valor total das exportações brasileiras; $X_{z j}=$ representa o valor das exportações mundiais do produto $j ; X_{z}=$ representa o valor total das exportações mundiais; $i=$ exportações brasileiras; $z=$ exportações mundiais; $j=$ uvas frescas.

Os resultados do índice podem variar de zero a infinito. Se for maior que 1, o país apresenta vantagem comparativa revelada. Se o resultado for menor que 1 , o país não apresenta vantagem comparativa revelada. Sendo o resultado igual a 1, o país não tem vantagem e nem desvantagem no comércio do produto. Quanto maior for o índice, maior a vantagem comparativa do país.

\section{Taxa de Cobertura}

A Taxa de Cobertura (TC) é utilizada para relacionar as exportações e as importações e define-se como o quociente entre as exportações e as importações de determinado bem. Tal indicador é obtido pela Equação (2):

$$
T C_{r j}=\frac{X_{r j}}{M_{r j}}
$$

Em que: $X_{r j}=$ valor das exportações brasileiras do produto $j ; M_{r j}=$ valor das importações brasileiras do produto $j$; e $j=$ uvas frescas.

Se o resultado for maior que 1, as exportações superam as importações, e isso significa que o produto contribui para o superávit da balança comercial. Quando o resultado for menor que 1 , as importações superam as exportações, e o produto não está contribuindo para o aumento do saldo da balança comercial. 


\section{Índice de Orientação Regional}

O Índice de Orientação Regional (IOR) se baseia nos estudos de Yeats (1997) em um contexto de mudanças nos padrões de comércio com os acordos regionais. É expresso pela Equação (3):

$$
I O R_{r j}=\frac{\left(X_{r j} / X_{t r}\right)}{\left(X_{o j} / X_{t o}\right)}
$$

Em que: $X_{r j}=$ valor das exportações brasileiras do produto $j ; X_{t r}=$ valor total das exportações brasileiras intrabloco; $X_{o j}=$ valor das exportações brasileiras do produto $j$ extrabloco; $X_{\text {to }}=$ valor total das exportações brasileiras extrabloco; e $j$ = uvas frescas.

O IOR, assim como o IVCR, varia de zero a infinito. Se o resultado for 1, existe uma mesma tendência para exportar o produto para membros do bloco e não membros do bloco. Se o indicador de orientação regional apresentar valores crescentes ao longo do tempo, existe uma tendência para exportar mais para o bloco.

\section{Fonte de dados}

Para o cálculo dos indicadores, as informações referentes às exportações e às importações brasileiras de uva, bem como às exportações brasileiras totais, foram obtidas no Sistema para Consulta e Extração de Dados do Comércio Exterior Brasileiro (COMEXSTAT), o qual se baseia na declaração de exportadores e importadores. Utilizou-se, ainda, a Nomenclatura Comum do Mercosul (NCM) de oito dígitos, com seu respectivo código (0806.10.00), que corresponde a uvas frescas. Para obtenção de dados referentes às exportações mundiais de uva e às exportações mundiais totais, utilizaram-se os sites da Food and Agriculture Organization of the United Nations (FAO) e do The World Bank.

\section{Análise e discussão dos resultados}

\section{Caracterização do mercado exportador de uva brasileiro}

Os estados da Bahia e de Pernambuco são os principais exportadores brasileiros de uva. De acordo com dados da Empresa Brasileira de Pesquisa Agropecuária 
(Embrapa) (2019), a produção de uvas no Brasil, em 2018, foi de 1.592.242 toneladas, $5,22 \%$ menor que em 2017. Destaca-se que a Região Sul é a maior produtora desse fruto, representando 58,91\% do total produzido pelo país, no entanto, essa produção é destinada à fabricação de vinhos e espumantes. A Região Nordeste é a segunda maior produtora de uva e, em 2018, contribuiu com $31,52 \%$ da produção total do país. No mesmo ano, a região apresentou aumento de $12,78 \%$ em sua produção, comparado ao ano anterior. A maior parte desta produção concentra-se no Vale do Rio São Francisco, sendo que a produção de uvas no estado de Pernambuco foi de 423.382 toneladas no ano de 2018, apresentando um crescimento de $8,48 \%$, comparado ao ano anterior, e, no estado da Bahia, essa produção foi de 75.378 toneladas, 47,54\% maior quando comparada a 2017 (MELLO, 2018).

Destaca-se que a exportação de uva, entre os anos 2017 e 2019, tem permanecido constante (conforme observado na Figura 1). Ao analisar o cenário brasileiro de exportações de uva, é possível observar que, do ano 2000 a 2003, as exportações do produto aumentaram cerca de $22 \%$. Em 2004, ocorreu uma diminuição das exportações do produto, e isso se deve a condições climáticas decorrentes de fortes chuvas, que provocaram redução da oferta de uva bem como dos padrões de qualidade do produto para exportação, conforme apontado por Veloso, Correa e Lima-Filho (2009) e Silva, Ferreira e Lima (2016). No período de 2005 a 2008, as exportações desse produto voltaram a crescer e apresentaram um crescimento de cerca de $1.310 \%$, se comparado ao ano de 2000. Destaca-se que, em 2008, ocorreu o maior volume de exportações desse produto, atingindo um valor de US $\$ 171 \mathrm{mi}-$ lhões, e o equivalente a 82 milhões de quilogramas de uva.

No entanto, em 2009, houve uma redução brusca do volume de exportações de uva, uma diminuição de cerca de 35,6\%. Segundo Mello (2009), as exportações brasileiras de uva decaíram em 2009, cerca de 54.560 toneladas (33,65\%) a menos do que no ano anterior. Isso se deve à crise mundial que ocorreu em 2008, situação que provocou desestímulo e abandono de alguns produtores de parreirais do Nordeste brasileiro, que não produziram em 2009. Além disso, as fortes chuvas que ocorreram no Vale do Rio São Francisco provocaram rachaduras de bagas, tornando parte da produção inapropriada para exportação. 
Figura 1 - Exportações brasileiras de uva no período de 2000 a 2019

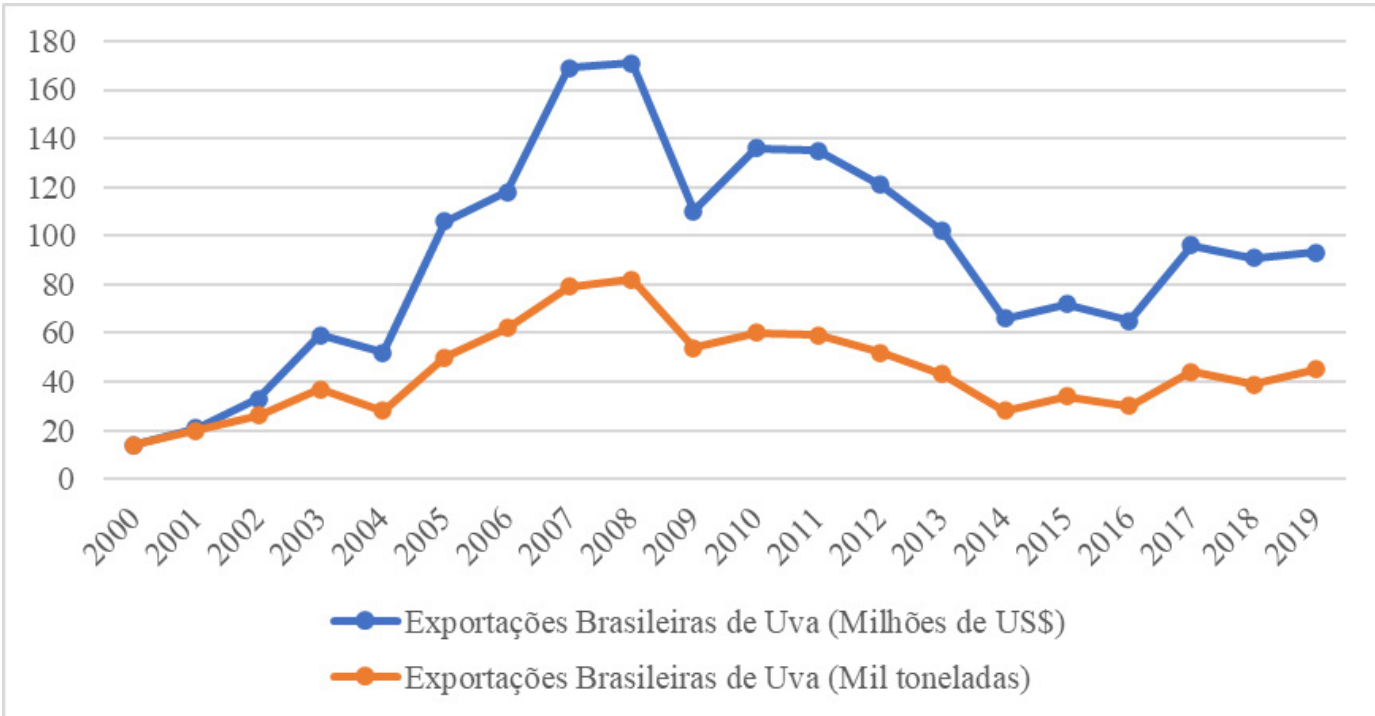

Fonte: COMEXSTAT (BRASIL, 2020).

Em 2010, as exportações tiveram um leve aumento, no entanto, em 2012, tornaram a cair, situação que perdurou até o ano de 2014. A queda das exportações nesse período é reflexo da crise financeira dos Estados Unidos e da queda do dólar, em 2008, no entanto, em 2012, a taxa de câmbio foi o principal fator que contribuiu para a queda das exportações de uva (SILVA; FERREIRA; LIMA, 2016). No ano de 2013, a alta no preço foi muito pequena, além disso, a venda da uva para o mercado externo caiu devido ao prolongamento da colheita nos Estados Unidos, um dos principais importadores do produto, e na Grécia, que abastecia os países da Europa (AMARAL et al., 2016). Em 2014, ainda se presenciavam os reflexos dos últimos dois anos, além disso, a situação se agravou, pois a região do Vale do Rio São Francisco, principal produtora e exportadora de uva, ainda não havia recuperado todo o seu potencial produtivo, devido à quebra de safra nos dois últimos anos decorrentes do clima quente e seco (CEPEA, 2016).

Em 2015, o volume de exportação do produto voltou a apresentar crescimento, cerca de $18 \%$ se comparado a 2014, mantendo-se constante em 2016. Em 2017, ocorreu um novo crescimento no volume de exportações, cerca de $31 \%$ em comparação a 2016, mantendo-se constante até 2019. De acordo com o Centro de Estudos Avançados em Economia Aplicada (CEPEA) (2019), a participação do Brasil no 
mercado europeu apresentou um crescimento de 4\% em 2014 e de 6\% em 2018, e isso se deve, em parte, ao acordo de cooperação econômica Mercosul-União Europeia. Como ocorreu a isenção das tarifas da uva, também houve aumento da exportação desse produto a países europeus.

Diante disso, é possível perceber que os principais estados exportadores de uva brasileira são Pernambuco e Bahia, conforme se observa na Figura 2.

Figura 2 - Exportações dos estados da Bahia e de Pernambuco em relação aos demais estados brasileiros

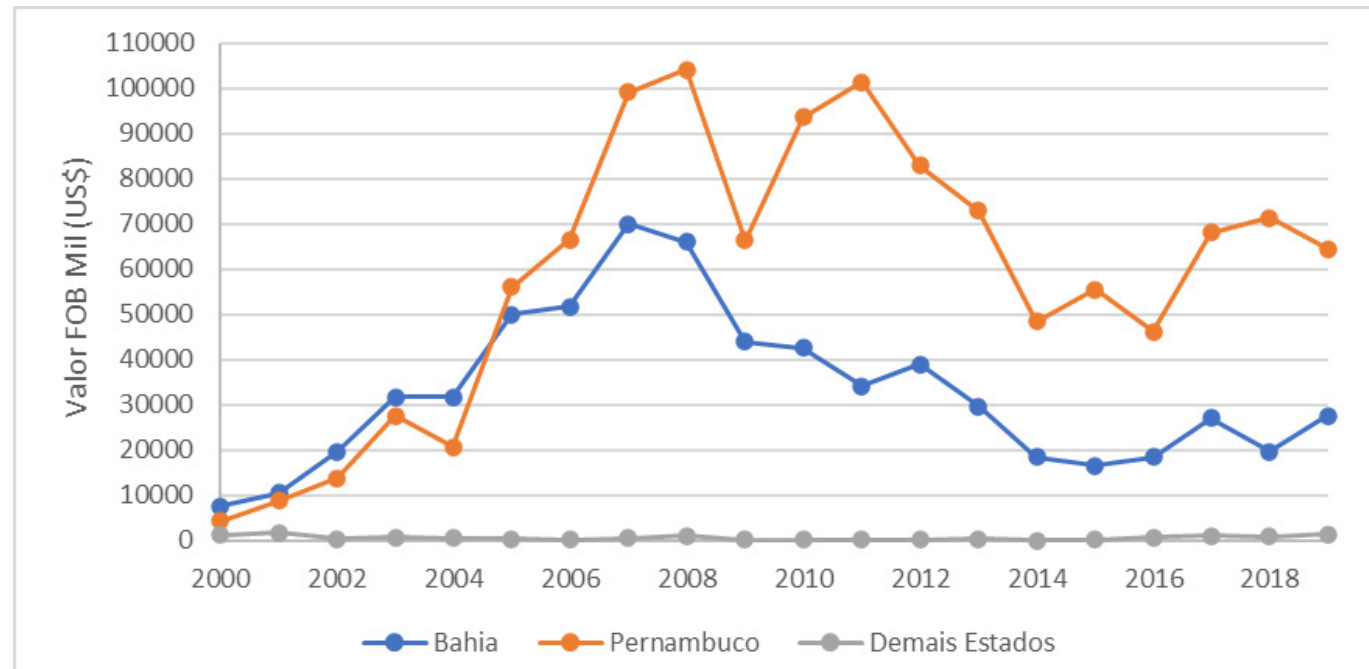

Fonte: COMEXSTAT (BRASIL, 2020).

Ao analisar a Figura 2, é possível perceber que a série histórica das exportações de uva dos estados é semelhante ao padrão apresentado pela série correspondente às exportações do Brasil, seguindo, dessa forma, os mesmos efeitos descritos anteriormente para o caso do Brasil. Além disso, ressalta-se que o volume de exportações dos dois estados, em 2019, correspondeu a cerca de 98,57\% do total exportado pelo país. De acordo com Silva e Coelho (2010), a produção de uva no Nordeste brasileiro concentra-se, sobretudo, na região do submédio do Vale do Rio São Francisco, localizada nos sertões de Pernambuco e da Bahia. Essa região é favorecida pelo alto potencial de recursos naturais e pelos altos investimentos públicos e privados em projetos voltados à irrigação, sendo por isso que esta cultura vem apresentando grande expansão ao longo dos anos nessa região. 
Os principais mercados de destinação da uva brasileira, no ano de 2019, foram Países Baixos (Holanda) (38,60\%), Reino Unido (31,76\%), Estados Unidos (17,38\%) e Alemanha (3,72\%), conforme apresentado na Figura 3.

Figura 3 - Principais países importadores de uva brasileira em 2019

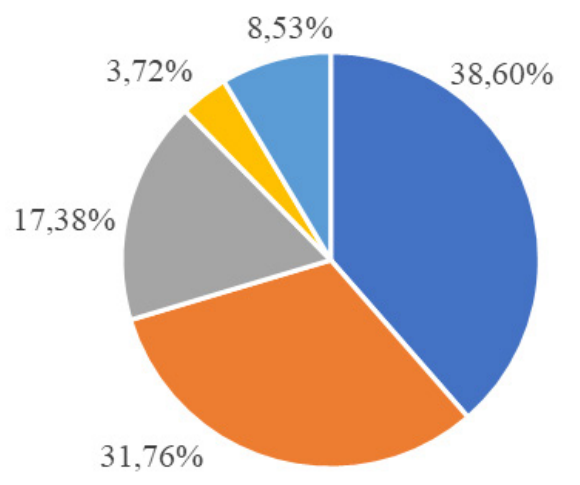

- Países Baixos (Holanda)

- Reino Unido

- Estados Unidos

- Alemanha

- Outros

Fonte: COMEXSTAT (BRASIL, 2020).

Destaca-se que o setor fruticultor brasileiro apresenta grande potencial de crescimento, no entanto, possui algumas limitações. De acordo com Carvalho (2009), as principais limitações apresentadas pelo setor de fruticultura brasileiro, principalmente pela Região Nordeste, são as dificuldades de adaptação do produtor aos padrões de exigências do mercado internacional, pois a fruticultura normalmente é uma prática do pequeno produtor, e este, muitas vezes, não possui condições financeiras para investir em sistemas de produção mais eficientes ou para se adaptar a determinados padrões de qualidade. Além disso, existem as questões climáticas e a falta de políticas que incentivem, por meio de linhas de crédito, a produção voltada ao mercado internacional.

Para as exportações da uva brasileira, cujo destino principal é a Europa, Aires e Julião (2017, p. 13) destacam que:

[...] o maior desafio está na janela de envio limitada em três meses, pois a safra grega vai até setembro, e, enquanto a Europa está produzindo, incide uma tarifa de importação sobre o produto brasileiro, o que reduz de forma significativa sua competitividade, e, a partir de novembro, a produção de uvas no Brasil é afetada pelo período típico de chuvas. 
Além disso, Palmieri e Barbieri (2019) apontam que, a depender do período do ano, a tarifa sobre a uva brasileira varia de $11,5 \%$ a $14 \%$, enquanto os principais concorrentes do Brasil já são isentos. Portanto, o acordo comercial entre o Mercosul e a União Europeia, com isenção de tarifas, teria alto impacto sobre as exportações da uva brasileira, com a possibilidade de ampliação das janelas de exportação.

\section{Análise dos indicadores de comércio internacional}

\section{Índice de Vantagem Comparativa Revelada}

Analisando a Tabela 1, que traz os resultados da aplicação do Índice de Vantagem Comparativa Revelada (IVCR) e a evolução desses resultados, pode-se afirmar que o Brasil possui vantagens comparativas nas exportações de uva, tendo em vista que, na maior parte do período estudado, o índice foi superior à unidade, entretanto, a partir de 2009, os resultados começaram a diminuir sistematicamente, revelando perda de competitividade, mas esse ciclo foi interrompido em 2017, quando cessou a queda e o valor do índice foi igual à unidade, sinalizando que o país pode estar recuperando a competitividade.

Tabela 1 - Índice de Vantagem Comparativa Revelada das uvas frescas brasileiras (2000-2017)

\begin{tabular}{l|c|c|c}
\hline \multicolumn{1}{c|}{ Anos } & IVCR & Anos & IVCR \\
\hline 2000 & 0,69 & 2009 & 1,72 \\
2001 & 0,96 & 2010 & 1,74 \\
2002 & 1,40 & 2011 & 1,44 \\
2003 & 2,11 & 2012 & 1,32 \\
2004 & 1,65 & 2013 & 1,06 \\
2005 & 2,56 & 2014 & 0,75 \\
2006 & 2,78 & 2015 & 0,85 \\
2007 & 3,20 & 2016 & 0,78 \\
2008 & 2,63 & 2017 & 1,00 \\
\hline
\end{tabular}

Fonte: elaboração dos autores com base nos dados da pesquisa, 2020.

Constata-se que, nos dois primeiros anos da série, 2000 e 2001, o resultado do índice foi menor que a unidade, o que significa desvantagem comparativa, entretanto, a partir de 2002, com uma maior inserção do Brasil no comércio internacional, o país passou a ter resultados superiores à unidade. De acordo com Vitti 
(2009), a partir dos anos 2000, frutas como a uva, o limão e a maçã, que até então eram pouco exploradas, ganharam maior espaço no comércio internacional devido à adoção de políticas governamentais, entre elas, incentivo à produção em áreas pouco exploradas como o Vale do Rio São Francisco, certificação da fruta, melhora da qualidade e dos meios de distribuição.

O ano de 2004 registrou uma "quebra" na tendência crescente do índice, pois ele diminuiu se comparado a 2003, e o valor das exportações também diminuiu, entretanto, isso se deve a condições climáticas. As fortes chuvas provocaram redução na oferta de uva, bem como redução dos padrões de qualidade do produto para exportação, conforme apontado por Veloso, Correa e Lima-Filho (2009). O melhor resultado do IVCR foi no ano de 2007, quando o índice atingiu o valor de 3,20, encerrando a trajetória crescente do IVCR. No ano seguinte, 2008, o Brasil registrou o maior volume de exportações de uva de todo o período analisado. No entanto, o IVCR foi menor do que no ano anterior, e isso se deve ao fato de que as exportações totais brasileiras, em 2008, apresentaram um aumento expressivo se comparado aos anos anteriores, proporcionalmente maior do que o aumento das exportações de uva, refletindo-se em queda do índice.

No ano de 2009, houve redução acentuada do índice, provavelmente em função da queda brusca das exportações. Como explicado na seção anterior, esta queda é reflexo das fortes chuvas que atingiram o Nordeste, mais especificamente o Vale do Rio São Francisco. Além disso, o mercado interno apresentou bom desempenho enquanto o mercado internacional sentia os reflexos da crise financeira, que acabou diminuindo a demanda por produtos importados (AIRES; JULIÃO, 2017). Conforme Oliveira, Lopes e Moreira (2011), também pode haver relação com as maiores exigências de supermercados europeus, principal mercado de destino da uva brasileira, para adoção de certificados que atestassem a qualidade do produto brasileiro e, assim, houve necessidade de ajustes na produção.

No período que compreende os anos de 2014 a 2016, o índice volta a apresentar resultados menores que a unidade, ou seja, a uva brasileira não poderia mais ser considerada competitiva no comércio internacional. De acordo com Barbieri et al. (2018), a baixa competitividade do Brasil nesse período é explicada por diversos fatores, entre eles, o fato da concorrência à uva brasileira ter aumentado muito na Europa, já que a janela atrativa de demanda ocorre no segundo semestre, quando finalizam as safras da Grécia e da Itália, entretanto, nesse período, países como Peru, Turquia e Namíbia também fornecem a fruta ao bloco, além disso, a janela de exportações para 
os Estados Unidos ficou mais estreita, pois houve prolongamento nas safras da Califórnia e do México. Por fim, períodos chuvosos durante a colheita da uva no Brasil limitaram os embarques, tanto pela redução do volume como da qualidade.

No ano de 2017, o IVCR foi exatamente igual à unidade, sinalizando que o produto pode estar voltando a ser competitivo no comércio internacional, ademais, as exportações aumentaram consideravelmente, se comparadas aos três anos anteriores. De acordo com Palmieri e Julião (2017), após a forte queda da receita obtida com frutas frescas a partir de 2009, o que não ocorreu somente no Brasil, o setor apresentou indícios de recuperação no mercado internacional. Segundo Barbieri et al. (2018), em 2017, as exportações de uva brasileira ganharam mais espaço em razão da introdução de novas variedades, podendo estender o calendário de exportação, e isso demonstra que a uva brasileira tem potencial para aumentar sua competitividade.

Além disso, houve investimento em pesquisa, visando ao melhoramento da qualidade da uva produzida na Região Nordeste, tornando possível a sua colheita ao longo de todo o ano. Ademais, esse melhoramento permitiu a elaboração de suco, algo que há pouco mais de seis anos não era viável, mesmo diante das condições favoráveis de solo e clima na região, principal exportadora do produto in natura (EMBRAPA, 2019).

\section{Taxa de Cobertura}

A taxa de cobertura, cujos resultados estão expostos na Tabela 2, correlaciona as exportações e as importações de determinado produto, por meio dela é possível saber se o país é comprador ou exportador do bem no comércio mundial.

Tabela 2 - Taxa de cobertura das uvas frescas brasileiras (2000-2017)

\begin{tabular}{c|c|c|c}
\hline \multicolumn{1}{c|}{ Ano } & TC & Ano & TC \\
\hline 2000 & 1,61 & 2009 & 5,10 \\
2001 & 3,55 & 2010 & 3,78 \\
2002 & 4,71 & 2011 & 2,64 \\
2003 & 11,84 & 2012 & 2,24 \\
2004 & 13,02 & 2013 & 1,73 \\
2005 & 16,12 & 2014 & 1,07 \\
2006 & 10,55 & 2015 & 1,45 \\
2007 & 11,34 & 2016 & 1,42 \\
2008 & 11,54 & 2017 & 2,46 \\
\hline
\end{tabular}

Fonte: elaboração dos autores com base nos dados da pesquisa, 2020. 
Durante todo o período analisado, as exportações brasileiras de uvas frescas superaram as importações, portanto, a contribuição da uva para o saldo da balança comercial brasileira sempre foi positiva. A trajetória dos resultados desse indicador foi crescente até 2005, quando atingiu o ápice, e o período entre 2006 e 2008 foi o melhor em termos de exportação, entretanto, as importações também aumentaram consideravelmente, o que levou a uma leve redução da taxa de cobertura.

Para Deleo et al. (2012), a partir de 2009, tornou-se nítida a preferência dos produtores, especialmente os do Vale do Rio São Francisco, pelo mercado nacional, e os fatores que influenciaram esta mudança foram a diminuição do poder de compra dos consumidores europeus e norte-americanos em função da crise de 2008, a ampliação do calendário de comercialização dos concorrentes, que acirrou a competição na janela de exportação brasileira, a consolidação da classe média no Brasil e o aumento do poder aquisitivo da população. Todos esses fatores foram cruciais para atrair o olhar dos produtores ao mercado interno, e, consequentemente, houve diminuição das exportações e da taxa de cobertura.

A queda da taxa de cobertura persistiu até 2014, quando atingiu o menor valor de toda a série. Para Oliveira, Pagliuca e Julião (2014), nesse ano, houve redução nas exportações de uva em função do embargo russo, que impediu a compra de frutas dos EUA, da União Europeia, da Austrália, do Canadá e da Noruega, o que elevou a disponibilidade de uva no continente europeu e diminuiu a demanda pela fruta brasileira. Outro fato que levou à diminuição das exportações da fruta, segundo a Companhia Nacional de Abastecimento (Conab) (2018), foi a crise produtiva enfrentada pelos produtores de uvas na safra de 2016, no Rio Grande do Sul, decorrente das fortes chuvas enfrentadas pelo estado, e, apesar da leve recuperação no ano de 2017, os últimos anos apresentam consequências desse período. Destaca-se, ainda, que a importação de uva pelo Brasil, inclusive vinda da Europa, também aumentou, fazendo com que a relação entre exportações e importações de uvas frescas ficasse muito próxima da unidade. Além disso, as importações brasileiras de uvas e seus derivados aumentam a cada ano, justificando a queda gradativa do índice. Isso se deve, em parte, às políticas de isenção tributária no comércio com os países integrantes do Mercosul e com o Chile, possibilitando, assim, a entrada de produtos estrangeiros a preços mais competitivos no mercado brasileiro (CONAB, 2018). 


\section{Índice de Orientação Regional}

O Índice de Orientação Regional (IOR), apresentado na Tabela 3, permite analisar se as exportações de determinado produto, neste caso a uva, estão orientadas para determinados países. Para o presente trabalho, foram escolhidos a Alemanha, os Estados Unidos, a Holanda e o Reino Unido, pois são os maiores importadores do produto, visto que foram responsáveis por $86 \%$ das importações da uva brasileira em 2017 (BRASIL, 2020).

Tabela 3 - Índice de Orientação Regional de uvas frescas brasileiras (2000-2017)

\begin{tabular}{c|c|c|c|c}
\hline Ano & IOR Alemanha & IOR Estados Unidos & IOR Holanda & IOR Reino Unido \\
\hline 2000 & 1,49 & 0,11 & 21,49 & 5,95 \\
2001 & 1,29 & 0,01 & 32,57 & 8,82 \\
2002 & 0,69 & 0,06 & 29,46 & 20,07 \\
2003 & 0,53 & 0,12 & 29,00 & 16,35 \\
2004 & 0,51 & 0,36 & 26,21 & 15,56 \\
2005 & 0,27 & 0,70 & 35,03 & 14,88 \\
2006 & 0,28 & 1,68 & 27,00 & 12,62 \\
2007 & 0,78 & 1,02 & 18,32 & 17,75 \\
2008 & 0,40 & 2,34 & 12,84 & 17,41 \\
2009 & 0,38 & 2,74 & 14,11 & 15,73 \\
2010 & 0,30 & 3,05 & 14,02 & 16,20 \\
2011 & 0,59 & 4,09 & 18,93 & 17,59 \\
2012 & 0,68 & 1,86 & 14,15 & 21,28 \\
2013 & 2,36 & 0,63 & 19,57 & 31,96 \\
2014 & 2,22 & 0,02 & 19,69 & 35,70 \\
2015 & 4,36 & 0,20 & 20,38 & 36,20 \\
2016 & 3,87 & 0,18 & 29,73 & 26,22 \\
2017 & 3,88 & 0,49 & & 24,05 \\
\hline
\end{tabular}

Fonte: elaboração dos autores com base nos dados da pesquisa, 2020.

Ao analisar a Tabela 3, observa-se que Holanda e Reino Unido sempre tiveram resultados bastante superiores à unidade, e, assim, as exportações estão mais orientadas para estes blocos, entretanto, o comportamento do índice durante o período é bastante instável. Verifica-se, então, que os países da União Europeia são os principais destinos da uva brasileira. Ressalta-se que esse bloco importou cerca de $67 \%$ do total de frutas exportadas em 2017 e cerca de $75 \%$ da uva embarcada. As maiores compras de uva foram efetuadas pelos Países Baixos (Holanda) (36\%) 
e pelo Reino Unido (32\%). O terceiro maior importador foi Estados Unidos (17\%) (BRASIL, 2020).

Com relação à Holanda, apesar de ser o maior importador e principal destino da uva brasileira, somente a partir de 2014 o índice apresentou crescimento ano após ano. Dentre os 110 países destinados à exportação de frutas em 2018, a Holanda se manteve na liderança, sendo o principal destino de frutas in natura e frutas e seus derivados (BRASIL, 2020). Os bons resultados da Holanda podem ser explicados pelo fato de que boa parte das frutas produzidas no Brasil destinadas à Europa passam pelo estratégico Porto de Roterdã, na Holanda, que é o maior do continente, ou seja, o país é um importante centro de distribuição de frutas na Europa (ABRAFRUTAS, 2019b). Além disso, a via marítima torna-se mais viável, ou é a que apresenta menor custo para transportar uvas para seu destino, e as vias área e rodoviária são meios de transporte utilizados por apenas $0,1 \%$ e $0,6 \%$, respectivamente, do total exportado de uvas brasileiras (FONSECA; XAVIER; COSTA, 2010).

No caso do Reino Unido, a trajetória de seus resultados é mais uniforme, mas também apresenta oscilações, mesmo assim, pode-se dizer que há uma forte tendência de exportar para este país. Conforme Rodrigues (2012), as exportações da uva brasileira apresentaram taxas de crescimento expressivas, e o país se tornou competitivo no mercado europeu devido à melhoria da qualidade da produção dessa fruta, que se tornou bastante aceita naquele mercado, sobretudo no Reino Unido. Nos últimos anos, o Brasil vem atendendo à exigência do mercado importador, visando à diminuição no nível de agrotóxicos e à preservação do meio ambiente, o que é valorizado pelas populações da Europa e do Reino Unido.

Quanto aos resultados de orientação regional da Alemanha, nos dois primeiros anos da série, com resultados superiores à unidade, as exportações da uva brasileira eram orientadas ao país, no entanto, entre 2002 e 2012, o índice ficou abaixo da unidade, e a recuperação veio a partir de 2013, com o melhor resultado em 2015. Desde então, o índice tem se mantido estável, o que significa que o Brasil exporta quantidade significativa de uvas para a Alemanha, mas não se pode afirmar que há tendência de crescimento ou diminuição das exportações intrabloco.

Segundo Roenne (2018, p. 35),

[...] o desempenho das exportações de frutas para a Alemanha tem sido modesto. Os dados demonstram decréscimo das importações alemãs, tendo como origem o Brasil, de 7\%, em relação ao valor, no período de 2012 e 2016 . No entanto as exportações de frutas brasileiras estão longe de esgotar as suas possibilidades de inserção e aumento no grande mercado que é a Alemanha. 
Percebe-se que os consumidores locais estão cada vez mais atentos à saúde, à qualidade e à segurança dos alimentos, de forma que o foco na promoção dos benefícios das frutas brasileiras para a saúde e a melhoria da qualidade destas poderiam impulsionar o crescimento do consumo na Alemanha.

Para os Estados Unidos, o indicador revelou-se superior à unidade apenas para o período de 2006 a 2012, e dados do Ministério da Economia, Indústria, Comércio Exterior e Serviços (BRASIL, 2020) demonstram que, desde 2011, o Brasil vem perdendo espaço no mercado norte-americano, e isso se reflete no Índice de Orientação Regional. Esta questão tem relação com o fato de que a produção de uva nos Estados Unidos, sobretudo no estado da Califórnia, principalmente das variedades tardias, tem aumentado, o que provocou a diminuição das exportações brasileiras da fruta para o mercado norte-americano (CEPEA, 2011). Outro fator que tem contribuído para a diminuição das exportações de frutas é que o mercado norte-americano tem dado preferência às frutas vindas do México, de forma que, no início de 2018, o mercado norte-americano se encontrava saturado de frutas mexicanas, o que também provocou queda no preço da fruta brasileira devido ao excesso de oferta (CEPEA, 2018).

Por fim, destaca-se que o mercado internacional, sobretudo o europeu, está se tornando cada vez mais exigente no que se refere à importação de frutas. Além disso, Peru e Índia apresentaram, nos últimos anos, crescimento expressivo no mercado mundial de uva, tomando parte do mercado brasileiro (AIRES; JULIÃO, 2017). Dessa forma, inserir-se em um mercado extremamente exigente e altamente competitivo não é uma tarefa banal, pois o mercado internacional de frutas está longe de ser facilmente dominado, e isso se deve às barreiras fitossanitárias e às preferências comerciais com mudanças relacionadas à produção, à comercialização, à legislação e à logística (RODRIGUES, 2012).

\section{Considerações finais}

O presente trabalho teve por objetivo analisar a competitividade e a orientação das exportações brasileiras de uva fresca durante o período dos anos 2000 a 2017. Para atingir esse objetivo, utilizaram-se o Índice de Vantagens Comparativas Reveladas (IVCR), a Taxa de Cobertura (TC) e o Índice de Orientação Regional (IOR), para os principais países importadores do bem. 
Os resultados, em termos de vantagens comparativas reveladas, demonstraram que, na maior parte do período analisado, a uva brasileira foi competitiva. Entretanto, nos últimos anos, especialmente a partir de 2009, os resultados do índice caíram sistematicamente, revelando perda de competitividade. O índice foi afetado principalmente pela crise internacional, por questões climáticas e por fatores externos, como preços e colheitas nos países concorrentes, que fizeram com que o produto brasileiro perdesse competitividade no comércio internacional. $\mathrm{O}$ resultado, no ano de 2017, sinaliza para uma recuperação do índice.

A taxa de cobertura demonstrou que o saldo da balança comercial de uvas sempre foi positivo, mesmo que, durante todo o período estudado, o Brasil tenha importado uva, as exportações sempre foram maiores. Portanto, o produto é um bom gerador de divisas ao país. A partir de 2009, com a economia internacional em crise, houve um maior direcionamento para o mercado interno e, por consequência, a taxa de cobertura diminuiu. Atingiu o menor resultado em 2014, em função do embargo russo, que reduziu a demanda pela uva brasileira na Europa. A partir de 2015, a taxa de cobertura apresentou uma leve recuperação, que persistiu nos anos seguintes. A conjuntura econômica interna e os investimentos realizados refletiram em aumento das exportações e melhora do índice.

Em relação ao Índice de Orientação Regional, foi possível observar que as exportações estão fortemente orientadas para os dois principais importadores da uva brasileira, que são Holanda e Reino Unido. Ademais, de 2013 em diante, as exportações tornaram-se orientadas para a Alemanha também. Com relação aos Estados Unidos, os resultados do IOR comprovam que, a partir de 2012, o Brasil perdeu espaço no mercado de uvas norte-americano.

Os resultados encontrados corroboram o fato de que o Brasil possui grande potencial na produção de uvas para exportação. Porém, para que se possa alcançar resultados melhores em termos de competitividade no comércio internacional, fazem-se necessários maiores investimentos em linhas de crédito, especialmente ao pequeno produtor, para que ele possa se adequar às exigências do mercado internacional, produzir de forma mais eficiente e tornar-se menos suscetível às questões climáticas. Além disso, a redução de tarifas sobre a importação da uva brasileira, fruto de acordos comerciais, teria alto impacto sobre as exportações do produto, pois a redução do preço aumentaria sua competitividade e possibilitaria a ampliação das janelas de exportação. 
Como limitação do trabalho, destaca-se que os índices são estáticos e, portanto, não incluem questões qualitativas, como barreiras comerciais, condições climáticas, preços, entre outros. Para uma análise mais robusta, sugere-se a utilização de Modelos de Equilíbrio Geral Computável e de Alocação Espacial, que permitem simular cenários mais complexos e mensurar o impacto de políticas econômicas.

\title{
Competitiveness and regional orientation of the Brazilian grape exports
}

\begin{abstract}
The purpose of this study is to analyze the competitiveness and the regional orientation of the fresh grapes exports produced in Brazil, in the period of 2000 to 2017, for this purpose, international trade indicators were used, as the Revealed Comparative Advantage (RCA), the Coverage Rate (CT) and the Regional Orientation Index (ROI). The results presented that, in most part of the analyzed period, Brazil had comparative advantage revealed. Besides, throughout this period the exports exceeded imports, and the exports had a strong orientation towards the two main importers of the product, Netherlands and United Kingdom. However, the product has been losing ground in international trade, therefore, it is necessary to have greater incentives for grape production, so the country can achieve greater insertion in this market that has great potential.
\end{abstract}

Keywords: Fresh grapes. Competitiveness. Orientation.

\section{Competitividad y orientación regional de las exportaciones brasileñas de uva}

\section{Resumen}

El propósito de este estudio es analizar la competitividad y la orientación regional de las exportaciones de uvas frescas producidas en Brasil, en el período de 2000 a 2017, para ello se utilizaron indicadores de comercio internacional, como la Ventaja Comparativa Revelada (RCA), la tasa de cobertura (CT) y el índice de orientación regional (ROI). Los resultados presentaron que, en la mayor parte del período analizado, Brasil tenía una ventaja comparativa revelada. Además, a lo largo de este período las exportaciones superaron a las importaciones, y las exportaciones tuvieron una fuerte orientación hacia los dos principales importadores del producto, Holanda y Reino Unido. Sin embargo, el producto ha ido perdiendo terreno en el comercio internacional, por lo que es necesario contar con mayores incentivos para la producción de uva, para que el país pueda lograr una mayor inserción en este mercado que tiene un gran potencial.

Palabras clave: Uvas frescas. Competitividad. Orientación. 


\section{Notas}

1 A Teoria das Vantagens Absolutas afirma que cada país deve especializar-se na fabricação de um bem, aquele que apresenta produção mais eficiente comparado a outros bens, de forma que as transações comerciais entre duas nações basear-se-iam na demanda de um produto cuja produção tem origem de uma vantagem absoluta, ou seja, a produção daquele bem é mais favorável para o país que exporta do que para o importador (CARMO; MARIANO, 2010).

2 A Teoria das Vantagens Comparativas afirma que cada nação deve se especializar na produção de determinado bem que for relativamente mais eficiente, quando comparado a outros bens, por meio da análise comparativa entre custos de produção daquele bem nos países considerados; e importação de bens que apresentem um custo de produção interna maior (CARMO; MARIANO, 2010).

\section{Referências}

ASSOCIAÇÃO BRASILEIRA DE PRODUTORES EXPORTADORES DE FRUTAS E DERIVADOS - ABRAFRUTAS. Clipping. 2019a. Disponível em: https://abrafrutas.org/2019/03/07/brasil-e-o-terceiro-maior-produtor-de-frutas-do-mundo-diz-abrafrutas/. Acesso em: 28 maio 2020.

ASSOCIAÇÃO BRASILEIRA DE PRODUTORES EXPORTADORES DE FRUTAS E DERIVADOS - ABRAFRUTAS. Clipping. 2019b. Disponível em: https://abrafrutas.org/2019/07/05/fruta-brasileira-tipo-exportacao/. Acesso em: 26 maio 2020.

ASSOCIAÇÃO BRASILEIRA DE PRODUTORES EXPORTADORES DE FRUTAS E DERIVADOS - ABRAFRUTAS. Dados e Estatísticas. 2020. Disponível em: https://abrafrutas. org/2020/01/28/8825/. Acesso em: 28 maio 2020.

AIRES, H. S.; JULIÃO, L. Uva: Brasil perde espaço, mas embarque pode subir com novas variedades. Revista Hortifruti Brasil, n. 163, p. 13, Piracicaba, SP, nov. 2017. Disponível em: https:// www.hfbrasil.org.br/br/revista/acessar/completo/ha-espaco-para-exportar-mais-a-uniao-europeia.aspx. Acesso em: 22 maio 2020.

ALVES, L. M. M. Uma análise das exportações da fruticultura cearense e brasileira: o caso do abacaxi e da melancia. Dissertação (Mestrado em Economia Rural) - Universidade Federal do Ceará, Fortaleza, 2009.

AMARAL, G. V. et al. O desempenho das exportações brasileiras de uva: uma análise da competitividade da região do vale do São Francisco no período de 2005 a 2014. Revista Cadernos de Aulas do LEA, Ilhéus, BA, n. 5, p. 1-17, nov. 2016.

BALASSA, B. Trade liberalization and "Revealed" comparative advantage. Oxford: Manchester School of Economic and Social Studies, 1965.

BARBIERI M. G. et al. Especial Frutas: Brasil tem potencial para ser mais forte no mundo das frutas. Revista Hortifruti Brasil, Piracicaba, SP, n. 184, p. 8, nov. 2018. Disponível em: https:// www.hfbrasil.org.br/br/revista/acessar/completo/especial-frutas.aspx. Acesso em: 22 jun. 2020.

BOWEN, H. P. On the Theoretical Interpretation of Indices of Trade Intensity and Revealed Comparative Advantage. Weltwirtschaftliches Archiv, v. 119, n. 3, p. 464-472, 1983.

BRANDÃO, F. S.; CEOLIN, A. C.; GIANEZINI, M.; RUVIARO, C. F.; DIAS, E. A.; BARCELLOS, J. A. J. Orientação para mercado externo do café brasileiro. Coffee Science, Lavras, v. 7, n. 3, p. 275-283, set./dez. 2012. Disponível em: http://www.sbicafe.ufv.br/handle/123456789/7924. Acesso em: 20 maio 2020. 
BRASIL. Ministério da Economia, Indústria, Comércio Exterior e Serviços. Estatísticas. 2020. Disponível em: http://comexstat.mdic.gov.br/pt/home. Acesso em: 05 maio 2020.

CARMO, E. C.; MARIANO J. Economia Internacional. 2. ed. São Paulo: Saraiva, 2010.

CARVALHO, D. Um gargalo perigoso - país sabe produzir, mas perde na hora de comercializar. Desafios do desenvolvimento - IPEA, 2009. Disponível em: https://www.ipea.gov.br/desafios/index.php?option=com_content\&view=article\&id=1228: catid=28\&Itemid=23. Acesso em: 19 maio 2020.

CEPEA. Exportação de Uva. 2016. Disponível em: https://www.hfbrasil.org.br/br/exportacao-de-uva.aspx. Acessado em: 19 maio 2020.

CEPEA. Hortifrúti/Cepea. Impactos do acordo Mercosul-UE ao mercado de uva. 2019. Disponível em: https://www.hfbrasil.org.br/br/hortifruti-cepea-impactos-do-acordo-mercosul-ue-ao-mercado-de-uva.aspx. Acesso em: 19 maio 2020.

CEPEA. Hortifrúti/Cepea. Exportação aos Estados Unidos registram lentidão em 2018. 2018. Disponível em: https://www.cepea.esalq.usp.br/br/diarias-de-mercado/manga-cepea-exportacao-aos-estados-unidos-registram-lentidao-em-2018.aspx. Acesso em: 07 jul. 2020.

CEPEA. Hortifrúti/Cepea. Uva: safra nordestina para exportação começa em setembro. 2011. Disponível em: https://cepea.esalq.usp.br/br. Acesso em: 07 jul. 2020.

COLLE, A. C.; CAETANI, M. I.; TRINDADE, C. S.; ALVIN, A. M. Análise das vantagens comparativas e orientação regional das exportações das carnes suína, bovina e de frango do Rio Grande do Sul entre 2000 e 2013. 2014. Disponível em: https:/www.fee.rs.gov.br/wp-content/ uploads/2014/05/201405267eeg-mesa15-analisevantagenscomparativasorientacaoregional.pdf. Acesso em: 14 maio 2020.

COMPANHIA NACIONAL DE ABASTECIMENTO - CONAB. Uva Industrial. 2018. Disponível em: https:/www.conab.gov.br/info-agro/analises-do-mercado-agropecuario-e-extrativista/analises-do-mercado/historico-mensal-de-uva. Acesso em: 02 jul. 2020.

DELEO, J. P. B. et al. Gestão Sustentável - Uva. Revista Hortifruti Brasil, Piracicaba, SP, n. 118, p. 8, nov. 2012. Disponível em: hfbrasil.org.br/br/revista/acessar/especial-uva-vale-do-saofrancisco-de-olho-no-consumidor-brasileiro.aspx. Acesso em: 24 jun. 2020.

SECRETARIA DE AGRICULTURA E ABASTECIMENTO DO PARANÁ - SEAB. Departamento de Economia Rural (DERAL). Prognóstico 2020. Fruticultura: Análise de Conjuntura. 2020. Disponível em: http://www.agricultura.pr.gov.br/sites/default/arquivos_restritos/files/documento/2020-01/fruticultura_2020.pdf. Acesso em: 14 maio 2020.

EMPRESA BRASILEIRA DE PESQUISA AGROPECUÁRIA - EMBRAPA. Ciência coloca o Nordeste no circuito de produção de suco de uva de qualidade. 2019. Disponível em: https://www. embrapa.br/busca-de-noticias/-/noticia/40698686/ciencia-coloca-o-nordeste-no-circuito-de-producao-de-suco-de-uva-de-qualidade. Acesso em: 07 jul. 2020.

FONSECA, H. V. P.; XAVIER, L. F.; COSTA, E. F. Análise das exportações de uvas frescas brasileiras: uma estimação gravitacional a partir do modelo de regressões aparentemente não relacionadas. Revista de Economia Agrícola, São Paulo, v. 57, n. 2, p. 81-98, 2010.

FOOD AND AGRICULTURE ORGANIZATION OF THE UNITED NATIONS. FAOSTAT. Disponível em: http://www.fao.org/faostat/en/\#data. Acesso em: 05 maio 2020.

GREMAUD, A. et al. Economia Brasileira Contemporânea. São Paulo: Atlas, 2010.

Teoria e Evidência Econômica - a. 26, n. 54, p. 7-32, jan./jun. 2020 
KRUGMAN, P. R.; OBSTEFELD, M. Economia internacional - teoria e política. São Paulo: Makron Books, 2001.

MELLO, L. M. R. Atuação do Brasil no Mercado Vitivinícola Mundial. 2009. Disponível em: http://www.diadecampo.com.br/zpublisher/materias/Materia.asp?id=21292\&secao=Artigos\%20 Especiais. Acesso em: 19 maio 2020.

MELLO, L. M. R. Vitivinicultura brasileira: Panorama 2018. Comunicado Técnico, v. 175, n. 1, p. 6, 2018.

OBSERVATORY OF ECONOMIC COMPLEXITY. Statistics. 2020. Disponível em: https://oec. world/pt/. Acesso em: 01 jun. 2020.

OLIVEIRA, F. V.; PAGLIUCA, L. G.; JULIÃO, L. Uva. Revista Hortifruti Brasil, v. 13, n. 140, nov. 2014. Disponível em: https://www.hfbrasil.org.br/br/revista/acessar/especial-uva-niagara-toma-espaco-da-uva-fina-em-sp.aspx. Acesso em: 25 maio 2020.

OLIVEIRA, J. E. M.; LOPES, P. R. C.; MOREIRA, A. N. Produção integrada no Vale do São Francisco: situação e perspectivas - a produção intergrada de uvas como caso de sucesso. CONBRAF - Congresso Brasileiro de Fitossanidade, Jabotical, SP, p. 6, 2011. Disponível em:

https://ainfo.cnptia.embrapa.br/digital/bitstream/item/38283/1/Eudes-palestras.pdf. Acesso em: 22 maio 2020.

PALMIERI, F. G.; BARBIERI, M. G. Acordo Mercosul-UE deve favorecer competitividade de fruta brasileira. Revista Hortifruti Brasil, n. 195, p. 9, Piracicaba - SP, nov. 2019. Disponível em:

https://www.hfbrasil.org.br/br/revista/acessar/completo/acordo-mercosul-e-ue-deve-favorecer-competitividade-do-br.aspx. Acesso em: 10 jun. 2020.

PALMIERI, F. G.; JULIÃO, L. Especial Frutas: Há espaço para exportar mais à UE? Revista Hortifruti Brasil, n. 163, p. 13, Piracicaba - SP, nov. 2017. Disponível em: https://www.hfbrasil. org.br/br/revista/acessar/completo/ha-espaco-para-exportar-mais-a-uniao-europeia.aspx. Acesso em: 22 jun. 2020.

RAINELLI, M. Nova teoria do comércio internacional. Bauru: EDUSC, 1998.

REZENDE FILHO, C. de B. História Econômica Geral. 9. ed. São Paulo: Contexto, 2008.

RODRIGUES, J. Competitividade das exportações brasileiras de frutas para o mercado europeu. 2012. 107 f. Dissertação (Programa de Pós-Graduação em Administração e Desenvolvimento Rural) - Universidade Federal Rural de Pernambuco, Recife, 2012.

ROENNE, V. V. O Mercado de Frutas na Alemanha. Embaixada do Brasil na Alemanha, Setor de Promoção Comercial, Pesquisa de Mercado - PMR. Berlin, 2018. Disponível em: https://investexportbrasil.dpr.gov.br/Arquivos/PesquisasMercado/PMR-Alemanha-Frutas-2018.pdf. Acesso em: 07 jul. 2020.

SALVATORE, D. Economia internacional. Rio de Janeiro: LTC, 1998.

SANTOS, J. L. S.; SOUSA, E. P. Competitividade das exportações brasileiras de melão. Revista de Política Agrícola, v. 26, n. 3, jul./ago./set. 2017.

SANTOS, J. L. S.; SOUSA, E. P. Competitividade das exportações brasileiras de banana. Revista Estudo \& Debate, v. 26, n. 2, 2019.

SILVA, P. C. G.; COELHO, R. C. Caracterização social e econômica da cultura da videira. LEÃO, PCS Cultivo da Videira, Embrapa Semiárido, Sistema de Produção, v. 2, 2010. 
SILVA, F. A. et al. Competitividade das exportações brasileiras de mamão, 1995 a 2008. Revista de Economia e Agronegócio, v. 9, n. 3, 2011.

SILVA, R. A. da; CORONEL, D. A.; LOPES, M. M.; BENDER FILHO, R. Competitividade das exportações nordestinas de frutas para a União Europeia (1999-2013). Revista de Administração da UEG, v. 6, p. 57-74, 2015.

SILVA, T. J. J.; FERREIRA, M. de O.; LIMA, J. R. F. A competitividade das exportações de manga e uva do Vale Submédio do São Francisco. Revista de Política Agrícola, v. 25, n. 4, out./nov./dez. 2016.

SILVA FILHO, L. A.; SANTOS, P. L.; SILVA, J. L. M. Competitividade internacional na comercialização de uvas frescas de Pernambuco. Perspectiva Econômica, v. 13, n. 1, p. 44-58, 2017.

THE WORLD BANK. Goods exports (BoP, current US\$). Disponível em: https://data.worldbank. org/indicator/BX.GSR.MRCH.CD?view=chart. Acesso em: 05 maio 2020.

VELOSO, A. F.; CORREA, C. C.; LIMA-FILHO, D. O. Desempenho das exportações brasileiras de uva de mesa no período de 1990 a 2005. Informações Econômicas, SP, v. 39, n. 2, fev. 2009.

VITTI, A. Análise da competitividade exportações brasileiras de frutas selecionadas no mercado internacional. Tese (Mestrado em Economia Aplicada) - Universidade de São Paulo, Piracicaba, 2009.

WILLIAMSON, J. A economia aberta e a economia mundial: um texto de economia internacional. Rio de Janeiro: Campus, 1998.

YEATS, A. Does Mercosur's Trade Performance Raise Concerns about the Effects of Regional Trade Arrangements? Policy Research Working Paper, The World Bank, n. 1729, 1997. 